\title{
CHANGES IN NANOMECHANICAL PROPERTIES AND ADHESION DYNAMICS OF ALGAL CELLS DURING THEIR GROWTH
}

\author{
Flavien Pillet ${ }^{a}$, Etienne Dague ${ }^{b}$, Jadranka Pečar Ilićc , Ivica Ružićc, Marie-Pierre Rols ${ }^{a}$, Nadica \\ Ivošević DeNardis ${ }^{c *}$
}

a Université de Toulouse, UPS; IPBS; F-31077 Toulouse, France, Flavien.Pillet@ipbs.fr, MariePierre.Rols@ipbs.fr

${ }^{b}$ LAAS-CNRS, Université de Toulouse, CNRS,Toulouse, France, edague@laas.fr

c Ruđer Bošković Institute, POB 180,10002 Zagreb,Croatia,pecar@irb.hr,ruzic@irb.hr, ivosevic@irb.hr

*Corresponding author:

Tel: $+38514561-128$

Fax: +385 1 4680-242

E-mail address: ivosevic@irb.hr (N. Ivošević DeNardis)

\begin{abstract}
Nanomechanical and structural characterizations of algal cells are of key importance for understanding their adhesion behavior at interfaces in the aquatic environment. We examine here the nanomechanical properties and adhesion dynamics of the marine, unicellular, green flagellate Dunaliella tertiolecta in laboratory culture. Mechanical properties of motile cells are hard to access while keeping cells viable, and studies to date are limited. Immobilization of negatively charged cells to a positively charged substrate enables high-resolution imaging and nanomechanical measurements. Cells in exponential phase possess a large cell volume as imaged by AFM, in agreement with the large amount of amperometrically measured displaced charge at the interface. Cells are stiffer and more hydrophobic in exponential than in the stationary phase. Differences in the critical interfacial tensions of adhesion of cells in exponential and stationary phase show the analogy with adhesion of hydrophobic droplets of organic liquids. Differences in the kinetics of adhesion and spreading of cells at the interface are attributed to their volume and nanomechanical properties that vary during cell aging. In the future, cell mechanical properties could be considered as a marker for environmental stress in order to better understand viability and adaptation strategies of algal populations in aquatic systems.
\end{abstract}

\section{Keywords}

AFM, cell adhesion, chronoamperometry, kinetic, mathematical model, nanomechanics

\section{Highlights}

For the first time, nanomechanical properties of motile algal cell are determined.

Loss of elasticity and hydrophobicity indicates aging process of cell culture.

Dynamics of algal cell adhesion at the interface is faster in aged culture. 


\section{Introduction}

Single-celled algae play a fundamental role in the aquatic ecosystem, and they are sensitive to environmental changes. Many stressors (e.g. salinity, temperature, $\mathrm{pH}$, light, nutrients, pollutants, toxicants) in the aqueous environment affect algal cell growth, adaptation, physiological activity, and complex biochemical processes in the cell, which may have consequences in the food web structure. In addition to their ecological roles as oxygen producers and as the food base for almost all aquatic life, algae are economically important for biofuel production and as sources of food and pharmaceutical and industrial products. The unicellular green flagellate Dunaliella tertiolecta $(D$. tertiolecta) is widespread in aquatic ecosystems due to their tolerance to a wide range of salinities, light intensities, and temperatures [1]. Dunaliella lacks a rigid polysaccharide cell wall and is enclosed by a thin elastic plasma membrane covered by a mucous surface coat [2]. This membrane elasticity and the lack of a rigid cell wall permits rapid cell volume changes in response to variations in osmotic pressure [3]. Interest in these features has driven an increase in fundamental and biochemical research on Dunaliella.

Within this context, Atomic Force Microscopy (AFM) in liquid is a cutting edges technology to observe the morphological, mechanical and adhesion properties of living cells [4], as previously published in bacteria [5]. Several research groups employ AFM to investigate the morphology and nanomechanical properties of marine diatom cells, and the supramolecular organization of their extracellular biopolymers [6-9]. Mechanical properties of algal cells are critical determinants of their adhesion behavior at interfaces in the aquatic environment. A convenient way to study cell adhesion at the model interface is electrochemically with chronoamperometry. Chronoamperometry at the model charged interface is based on sensing of the interfacial properties, hydrophobicity, and supramolecular organization of particles rather than on the chemical composition [10]. The model liquid interface mimics interaction between fluid interfaces in contact while applied electrode potential corresponds to the electric field strength that act on the biological membranes [11-14]. Recently, we studied the adhesion dynamics of the Dunaliella cell and its plasma membrane vesicles at the charged interface through detection of amperometric signals on a time scale of milliseconds. Interpretation of the amperometric signals of cell and vesicles by a reaction kinetics model enables a better understanding of the sequence of the steps involved in cell adhesion at the interface [13,1517]. We showed that the time constants for plasma membrane vesicle adhesion are shorter than those for the algal cell. The difference in adhesion dynamics between the corresponding systems is associated with released intracellular content which is missing in the case of rupture and spreading of vesicles, filled with aqueous electrolyte solution. We report here a comprehensive biophysical approach to examine nanomechanical properties and adhesion dynamics during two phases of $D$. tertiolecta cell growth (exponential vs. stationary), utilizing adapted protocol for the attachment of motile algal cells in order to obtain previously unavailable quantitative nanomechanical measurements. The information obtained from the complementary surface methods and the mathematical model will contribute to a better understanding of the importance of surface properties in cell adhesion at charged interfaces.

\section{Experimental}

\subsection{Cell suspensions}

We used a laboratory culture of the unicellular marine algae Dunaliella tertiolecta Butcher (Chlorophyceae). The cells (maximum dimension 6-12 $\mu \mathrm{m}$ ) were grown in seawater enriched with F-2 medium [18] in batch culture under laboratory ambient conditions. The algae growth was followed by measuring the absorbance at $425 \mathrm{~nm}$. Algae were collected in exponential phase at day 5 and in stationary phase at day 20 . The cells were separated from the growth medium by mild centrifugation $(1500 \mathrm{~g}, 5 \mathrm{~min})$. The pellet was washed several times with filtered seawater. Stock 
suspension contained 1-6 $\times 10^{7}$ cells $/ \mathrm{mL}$. Cell density and viability were monitored by light microscopy.

\subsection{Atomic force microscopy}

AFM experiments were performed in quantitative imaging mode, QI [19] with a Nanowizard III (JPK Instruments, Germany). NPG-10 gold cantilevers (Bruker, Germany) were used, with a spring constant measured around $0.05 \mathrm{~N} / \mathrm{m}$. To evaluate the hydrophobicity, adhesion measurements were performed with cantilevers functionalized by 1-dodecanethiol (Sigma-Aldrich, France), as described previously [20,21]. Briefly, to generate a functionalized AFM tip, the gold cantilevers were first activated by immersion for $15 \mathrm{~min}$ in a mixture of $\mathrm{H}_{2} \mathrm{O}_{2}(30 \%), \mathrm{NH}_{3}(30 \%)$, and deionized water, in a 1:1:5 ratio $(\mathrm{v} / \mathrm{v} / \mathrm{v})$. The gold cantilevers were then immersed for $16 \mathrm{~h}$ in absolute ethanol containing $1 \mathrm{mM}$ of 1-dodecanethiol, rinsed with ethanol, and dried with nitrogen. A force of $2.5 \mathrm{nN}$ was applied for the AFM measurements. The calibration was performed with approach curves from the glass stiff support. Topography and elasticity were collected with the approach curves, and adhesion with the retract curves. Examples of approach curves (from glass stiff support and alga cell) were shown in Supplementary Figure 1. AFM analyses were carried out with the JPK Data processing software. Student's t-test was used for statistical significance.

\subsection{Sample preparation for AFM measurements}

For immobilization of the algae cells, glass slides were prepared as follows [5,22]. The slides were plasma-activated in the flow from a Pico plasma generator (Diener) for $5 \mathrm{~min}(50 \mathrm{~W}, 0.5 \mathrm{mbar}$, room temperature). On the plasma-treated slides were added a water solution containing $0.2 \%$ polyethylenimine (Sigma-Aldrich) and incubated for 1 hour in a closed Petri dish. The slides were then washed with deionized water and dried with nitrogen. Aliquots of algal cell suspension were placed on the dried, coated slides for $30 \mathrm{~min}$, after which non-immobilized algae were removed by rinsing with filtered seawater $(0.2 \mu \mathrm{m})$.

\subsection{Electrochemical measurements}

Dropping mercury electrode (DME) had a drop-life of 2.0 seconds, flow rate of $6.0 \mathrm{mg} / \mathrm{s}$ and a maximum surface area of $4.57 \mathrm{~mm}^{2}$. All potentials are referred to an $\mathrm{Ag} / \mathrm{AgCl}(0.1 \mathrm{M} \mathrm{NaCl})$ reference electrode, which was separated from the measured dispersion by a ceramic frit. Electrochemical measurements were performed using a PAR 174A Polarographic Analyzer interfaced to a computer. The potentiostat PAR 174A has two main parts: the voltage source and the measuring circuit. It was determined that the measuring circuit is the slower of the two components, and its rise time was measured by applying a signal with negligible rise time to its input, with the selector set on dummy cell mode. The rise time of the measuring circuit determined for different current ranges has a value of $0.1 \mathrm{~ms}$. Thus, the time constant of the PAR $174 \mathrm{~A}$ is $0.045 \mathrm{~ms}$. The acquisition of analog signals was performed with a DAQCard-AI-16-XE-50 (National Instruments) input device, and the data were analysed using an application developed in LabView 6.1. Current-time (I-t) curves over 50 mercury drop lives were recorded at constant potentials with temporal resolution of $50 \mu$ s. All experiments on cell suspensions were performed in deaerated $0.1 \mathrm{M} \mathrm{NaCl}$ at $20^{\circ} \mathrm{C}$ under purging with nitrogen. The measured signal has a specific waveform represented as a difference between two exponential functions of time. Approximating the measuring signal with a linear or an exponential function is the preferred way to analyze such a waveform; in this case the influence of the time constant of the potentiostat is much smaller than for the step function. Such an approximation introduces a delay and a slight change in amplitude of the output signal, but it enables the measurement of the time constants of the process even if they are comparable to the time constant of the potentiostat.

\subsection{Electrochemical method}


Adhesion and spreading of organic particles (such as droplets, lipid vesicles, cells) on a charged mercury/water interface cause double-layer charge displacement from the inner Helmholtz plane, and the transient flow of compensating current can be recorded as an amperometric signal. Each amperometric signal corresponds to the adhesion of a single particle from suspension [23-25]. The random occurrence of the adhesion events is due to the spatial heterogeneity inherent to a dispersed system and to the stochastic nature of particle-electrode encounters. At a given potential, the current amplitude reflects the size of the adhered particle, and the signal frequency reflects the particle concentration in the suspension $[10,11,23,26]$. The lower size-detection limit is $\geq 3 \mu \mathrm{m}$ under deaerated conditions. Signals are defined by their amplitude (i.e. peak of adhesion signal), $I_{\mathrm{m}}$, and duration, $t_{\mathrm{d}}$, as well as by displaced charge, $q_{\mathrm{D}}[11,24,26]$. The displaced double-layer charge is obtained by integrating the area under the signal:

$q_{\mathrm{D}}=\int_{t_{i}}^{t_{i}+t_{d}} I \mathrm{~d} t$

If charge displacement is complete, which leads to the formation of an organic layer, the area of the contact interface, $A_{\mathrm{c}}$, is determined from the amount of displaced charge:

$$
A_{\mathrm{c}}=\frac{q_{\mathrm{D}}}{\sigma_{12}}
$$

where $\sigma_{12}$ is the surface charge density of the mercury/aqueous electrolyte. According to the modified Young-Dupré equation, the total Gibbs energy of interaction between an organic droplet and the aqueous mercury interface is

$-\Delta G=A\left(\gamma_{12}-\gamma_{23}-\gamma_{13}\right)$

where $\gamma_{12}, \gamma_{13}$ and $\gamma_{23}$ are the interfacial tensions at the mercury/water, mercury/organic liquid, and water/organic liquid interfaces, respectively. The expression in parentheses is the spreading coefficient $\left(S_{132}\right)$ at the three-phase boundary [27]. When $S_{132}>0$, attachment and spreading are spontaneous processes, while when $S_{132}<0$, spreading is not spontaneous. The critical interfacial tension of adhesion $\left(\gamma_{12}\right)_{c}$ defined by $S_{132}=0$ will be $\left(\gamma_{12}\right)_{c}=\gamma_{13}+\gamma_{23}$.

\section{Theory}

The kinetics of organic particle adhesion to a charged interface can be described as a process involving three steps reported in detail previously $[13,16,17]$. Briefly, the three-step adhesion process is illustrated by four states: initial intact state $(A)$, two intermediate states $(B, C)$, which could be associated with deformation and rupture, and the final state of product formation $(D)$. The three-step process is represented by the following reaction scheme:

$$
A \underset{k_{2}}{\stackrel{k_{1}}{\rightleftarrows}} B \underset{k_{4}}{\stackrel{k_{3}}{\rightleftarrows}} C \underset{k_{6}}{\stackrel{k_{5}}{\rightleftarrows}} D
$$

This reaction scheme involves four states of the organic particle in contact with the charged interface, where $k_{1}, k_{3}$, and $k_{5}$ are the forward rate constants, while $k_{2}, k_{4}$, and $k_{6}$ are the backward rate 
constants. The reaction scheme is represented by a set of four differential equations in terms of the rate constants:

$\frac{\mathrm{d} A}{\mathrm{~d} t}=-k_{1} A+k_{2} B$

$\frac{\mathrm{d} B}{\mathrm{~d} t}=k_{1} A-\left(k_{2}+k_{3}\right) B+k_{4} C$

$\frac{\mathrm{d} C}{\mathrm{~d} t}=k_{3} B-\left(k_{4}+k_{5}\right) C+k_{6} D$

$\frac{\mathrm{d} D}{\mathrm{~d} t}=k_{5} C-k_{6} D$

with initial conditions: at $t=0, A=A_{0}, B=C=D=0$, and the corresponding continuity relation A $+\mathrm{B}+\mathrm{C}+\mathrm{D}=\mathrm{A}_{0}$. From these differential equations the analytical solutions for the individual states ( $A, B, C$, and $D$ ) in the time domain can be derived. The solution for the final state $D$ can be obtained in the following form:

$$
\begin{aligned}
D & =D_{0}\left[1-\exp \left(-\frac{t}{\tau_{0}}\right)\right]-D_{1}\left[1-\exp \left(-\frac{t}{\tau_{1}}\right)\right]+D_{2}\left[1-\exp \left(-\frac{t}{\tau_{2}}\right)\right] \\
& =D_{\infty}-D_{\infty}\left[\frac{\tau_{0}^{2} \exp \left(-\frac{t}{\tau_{0}}\right)}{\left(\tau_{1}-\tau_{0}\right)\left(\tau_{2}-\tau_{0}\right)}-\frac{\tau_{1}^{2} \exp \left(-\frac{t}{\tau_{1}}\right)}{\left(\tau_{1}-\tau_{0}\right)\left(\tau_{2}-\tau_{1}\right)}+\frac{\tau_{2}^{2} \exp \left(-\frac{t}{\tau_{2}}\right)}{\left(\tau_{2}-\tau_{0}\right)\left(\tau_{2}-\tau_{1}\right)}\right]
\end{aligned}
$$

where $D_{0}, D_{1}$ and $D_{2}$ are the corresponding pre-exponential constants, and $D_{\infty}=k_{1} k_{3} k_{5} \tau_{0} \tau_{1} \tau_{2} A_{0}$ represents the equilibrium value of the final state. For the analysis of amperometric measurements, Eq. (9) is transformed to its electrical equivalent, where the amount of product, $D$, and the rate of product formation, $\mathrm{d} D / \mathrm{d} t$, correspond to charge, $Q$, and current, $I$, respectively [14]. Thus,

$$
\begin{aligned}
& Q(t)=Q_{\infty}-Q_{0} \exp \left(-\frac{t}{\tau_{0}}\right)+Q_{1} \exp \left(-\frac{t}{\tau_{1}}\right)-Q_{2} \exp \left(-\frac{t}{\tau_{2}}\right) \\
& =Q_{\infty}-Q_{\infty}\left[\frac{\tau_{0}^{2} \exp \left(-\frac{t}{\tau_{0}}\right)}{\left(\tau_{1}-\tau_{0}\right)\left(\tau_{2}-\tau_{0}\right)}-\frac{\tau_{1}^{2} \exp \left(-\frac{t}{\tau_{1}}\right)}{\left(\tau_{1}-\tau_{0}\right)\left(\tau_{2}-\tau_{1}\right)}+\frac{\tau_{2}^{2} \exp \left(-\frac{t}{\tau_{2}}\right)}{\left(\tau_{2}-\tau_{0}\right)\left(\tau_{2}-\tau_{1}\right)}\right]
\end{aligned}
$$

and 


$$
\begin{aligned}
I(t) & =\frac{\mathrm{d} Q}{\mathrm{~d} t}=I_{0} \exp \left(-\frac{t}{\tau_{0}}\right)-I_{1} \exp \left(-\frac{t}{\tau_{1}}\right)+I_{2} \exp \left(-\frac{t}{\tau_{2}}\right) \\
& =Q_{\infty}\left[\frac{\tau_{0} \exp \left(-\frac{t}{\tau_{0}}\right)}{\left(\tau_{1}-\tau_{0}\right)\left(\tau_{2}-\tau_{0}\right)}-\frac{\tau_{1} \exp \left(-\frac{t}{\tau_{1}}\right)}{\left(\tau_{1}-\tau_{0}\right)\left(\tau_{2}-\tau_{1}\right)}+\frac{\tau_{2} \exp \left(-\frac{t}{\tau_{2}}\right)}{\left(\tau_{2}-\tau_{0}\right)\left(\tau_{2}-\tau_{1}\right)}\right]
\end{aligned}
$$

where $Q_{0}, Q_{1}, Q_{2}, I_{0}, I_{1}$ and $I_{2}$ are the corresponding pre-exponential constants. According to our methodology, four independent kinetic parameters define the model of the three-step process. Dependent parameters are calculated from three possible selected sets of independent parameters: i) $Q_{\infty}, \tau_{0}, \tau_{1}, \tau_{2}$; ii) $Q_{\infty}, \tau_{1}, \tau_{2}, Q_{2}$; and iii) $Q_{\infty}, \tau_{1}, \tau_{2}, I_{2}$. Finally, the best-fit curve of the threestep process corresponds to the reconstructed current transient using Eq. (11) and the determined kinetic parameters. The values of time, $t_{\mathrm{m}}$, and current amplitude, $I_{\mathrm{m}}$, are obtained numerically to check the agreement of the best-fit curve with the amperometric signal.

\section{Results}

\subsection{Cell mechanical characterization by AFM}

\subsubsection{Immobilization of live algal cells on modified glass substrate}

Mechanical characterization of $D$. tertiolecta cells has not been previously reported. In order to study the mechanical properties of live, motile algal cells by AFM, an efficient immobilization in a liquid environment is required. For this, glass slides coated with polyethylenimine (PEI) were used [5]. The PEI confers a positively charged surface [28], which allows an efficient immobilization of negatively charged D. tertiolecta [29] without damage to the cells. Cell immobilization was checked by optical microscopy prior to each AFM measurement (Fig. 1).

Here Fig. 1.

Cells are green, elliptically shaped with two flexible flagella. Flagella motion confirms the viability of attached (immobilized) cells.

\subsubsection{Effect of cell aging on the morphology, elasticity and hydrophobicity}

Topographic measurements were done by AFM to evaluate the algae shape, volume, and surface roughness at the nanoscale (Fig. 2).

Here Fig. 2.

AFM height images are shown for typical algae in exponential phase (Fig. 2a) and in stationary growth phase (Fig. 2c). The cross sections of attached cells (Fig. 2e) indicate difference in their vertical dimensions while maintaining cell integrity. Cell volumes were quantified from measurements of 8 algae in exponential phase and 6 in stationary phase (Fig. $2 \mathrm{~g}$ ). The mean volumes were $187 \pm 55 \mu \mathrm{m}^{3}$ in exponential phase and $129 \pm 32 \mu \mathrm{m}^{3}$ in stationary phase. The lack of a rigid cell wall permits rapid cell volume changes. The larger cell volume in exponential phase is caused by the growth of the mother cell preceding cell division. Nanoscale roughness was evaluated from high resolution images. Examples of algae surfaces are shown for cells in exponential phase (Fig. 2b) and in stationary phase (Fig. 2d). The cross sections (Fig. 2f) and the statistical analysis (Fig. 2h) revealed 
a similar roughness for exponential and stationary phase cells, with a mean of $27 \pm 10 \mathrm{~nm}$ and $24 \pm 8$ $\mathrm{nm}$, in exponential and stationary phase, respectively. Consequently, aging induces a decrease of algal volume but no change in roughness.

To explore the elasticity of the algae, successive force measurements were applied at $2.5 \mathrm{nN}$ by the AFM tips. Thousands of force curves were recorded and translated to pixel units to obtain elasticity maps given in Young's Modulus (YM) values at $200 \mathrm{~nm}$ depth. The elasticity of algae was compared in exponential (Fig. 3ace) and stationary phases (Fig. 3bdf).

\section{Here Fig. 3.}

The marked area in the AFM height images of algae (Fig. 3ab) shows the localization of elasticity (Fig. 3cd). The cross sections from the elasticity maps suggest a lower elasticity in stationary phase (Fig. 3e). In Fig. 3f, the YM values were extracted from all force curves (5204 curves from 8 elasticity maps of algae in exponential phase and 3636 curves from 6 elasticity maps of algae in stationary phase). Statistical analyses were performed from the mean values of each elasticity map. For the algae in exponential phase, the YM mean was $31 \pm 4.7 \mathrm{kPa}$. In stationary phase, the YM decreased by $39 \%$, with a mean of $19 \pm 7.3 \mathrm{kPa}$. This loss of elasticity is significant and suggests a molecular modification of the cell envelope during aging.

To evaluate the hydrophobic properties of the cell surface, chemical force measurements were performed with AFM tips functionalized with $-\mathrm{CH}_{3}$ groups (Fig. 4).

Here Fig. 4.

AFM height images of algae in exponential phase (Fig. 4a) and in stationary phase (Fig. 4b) exhibited the localization of adhesion force maps in Fig. 4c and Fig 4d, respectively. The cross sections reveal a dramatic decrease of hydrophobicity for algae in stationary phase (Fig. 4e). The mean of adhesion force was $0.7 \pm 0.05 \mathrm{nN}$ for algal cells in exponential phase (derived from analysis of 2704 curves from 4 algae) and $0.4 \pm 0.07 \mathrm{nN}$ for algal cells in stationary phase (derived from 3636 curves from 6 algae, Fig. 4f). Statistical analysis confirms loss of hydrophobicity.

\subsection{Chronoamperometric characterization of single cell}

Adhesion and spreading of individual $D$. tertiolecta cells at the charged interface is conveniently studied chronoamperometrically. In general, the algal cell attaches, deforms, ruptures, and spreads at the charged interface, causing charge displacement at the distance of the closest approach of about 0.3-0.5 nm [24]. Typical amperometric signals of D. tertiolecta cells in exponential and stationary phases recorded at a selected potential of $-400 \mathrm{mV}$ are shown in Fig. 5.

\section{Here Fig. 5.}

Applied potential of $-400 \mathrm{mV}$ is selected for the strongest attractive interaction acting between the charged electrode and cell (spreading coefficient $\mathrm{S}_{132}=22 \mathrm{~mJ} / \mathrm{m}^{2}$; electric field strength $25 \mathrm{MV} / \mathrm{m}$ ). The appearance of an amperometric signal is evidence for a single cell-electrode interaction. The signal reflects the rate of the final film formation at the interface. The shape of the amperometric signals of cells in exponential vs stationary phase are significantly different, suggesting that amperometric detection might be used to determine cell age in culture. At the potential of $-400 \mathrm{mV}$ (where electrode is positively charged) the amplitude direction is positive (i.e., at the potentials of $E>E_{\mathrm{pzc}}$ where $E_{\mathrm{pzc}}$ is the point of zero-charge). The selected signal of the algal cell in exponential phase has current amplitude $I_{\mathrm{m}}=0.37 \mu \mathrm{A}$ at time $t_{m}=0.46 \mathrm{~ms}$ and signal duration $t_{\mathrm{d}}=11.2 \mathrm{~ms}$. The total displaced charge, $q_{\mathrm{D}}$, and contact area of the interface, $A_{\mathrm{c}}$, are calculated using Eqs. (1) 
and (2). The total displaced charge is $1.29 \mathrm{nC}$, which corresponds to the contact area of the interface, $3.39 \times 10^{4} \mu \mathrm{m}^{2}$. D. tertiolecta cells in exponential phase adhere to the mercury electrode in $0.1 \mathrm{M}$ $\mathrm{NaCl}$ in the potential range from $-120 \mathrm{mV}$ to $-1100 \mathrm{mV}$. Therefore, the critical interfacial tensions of adhesion determined from electrocapillary data in $0.1 \mathrm{M} \mathrm{NaCl}$ correspond to $398 \mathrm{~mJ} / \mathrm{m}^{2}$ and 390 $\mathrm{mJ} / \mathrm{m}^{2}$ at the positively and negatively charged interfaces, respectively. Critical interfacial tensions for cell adhesion are not equal at the positively and negatively charged interfaces due to the contribution of electrostatic interactions between the negatively charged cell surface and the charged interfaces [14], and the specific adsorption of chloride ions at the positively charged interface. A detailed analysis of the amperometric signal of $D$. tertiolecta cells in stationary phase has been reported previously [13].

\subsection{Kinetic interpretation of amperometric signal of cell}

We apply the reaction kinetics model of the three-step process and the corresponding methodology to determine the kinetic parameters of adhesion and spreading from the amperometric signal of cells. The detailed procedure for extraction of kinetic parameters of adhesion process was described previously $[13,16]$. Analysis of the representative amperometric signal of a cell shown in Fig. 5 is presented in Fig. 6.

Here Fig. 6.

For amperometric signal analysis, it is essential to accurately determine the initial time when signal appears and the time when the signal ends, $t_{\mathrm{d}}$, i.e. when current value decreases below $1 \%$ of current amplitude $I_{\mathrm{m}}$. In the case of a large dispersion of current values, averaging of positive and negative deviations is performed. The selected amperometric signal is first divided into primary and secondary parts, and in addition the secondary part is separated into parts A and B for detailed analysis. The primary adhesion part of the signal is characterized by $I_{\mathrm{m} 1}, t_{\mathrm{m} 1}, t_{\mathrm{d} 1}(0.37 \mu \mathrm{A}, 0.46 \mathrm{~ms}$ and $2.84 \mathrm{~ms}$, respectively). The reconstructed current transient is obtained using the determined independent kinetic parameters $\left(\tau_{0}, \tau_{1}, \tau_{2}\right.$ and $\left.Q_{\infty 1}\right)$ and Eq. (11). The values of time constants $\tau_{0}, \tau_{1}, \tau_{2}$ denoting the attachment, deformation and spreading are $0.07 \mathrm{~ms}, 0.12 \mathrm{~ms}$, and $0.51 \mathrm{~ms}$, respectively (with accuracy between $0.02 \mathrm{~ms}$ and $0.03 \mathrm{~ms}$ determined from the set of signals analysed at -400 $\mathrm{mV}$ ). The amount of displaced charge, $Q_{\infty 1}$, corresponds to $0.32 \mathrm{nC}$.

Comparison of the selected amperometric signal of the cell in exponential phase recorded at -400 $\mathrm{mV}$ (circle) with the reconstructed current transient (red curve) is presented in Fig. 6. Agreement between the measured and the reconstructed current transient for the primary part of the signal is good at times $t<t_{\mathrm{i} 2 \mathrm{a}}$, (where $t_{\mathrm{i} 2 \mathrm{a}}=1.24 \mathrm{~ms}$ ), and the root-mean-square deviation is about $0.035 \mu \mathrm{A}$ (corresponding to $9.5 \%$ of signal amplitude $I_{\mathrm{m}}$ ). The amplitude $I_{\mathrm{m} 1}$ numerically determined from the reconstructed current transient (using Eq. 11) agrees well with the experimental value, $I_{\mathrm{m}}$ (deviation amounts to about $0.5 \%$ of the amplitude). The difference between the original experimental data and the reconstructed primary part of the signal can now be used for the analysis of the remaining secondary part of the signal. The secondary signal part appearing at times $t \geq t_{\mathrm{i} 2 \mathrm{a}},(1.24 \mathrm{~ms})$ could not be described by the reaction kinetics model, although it contains a significant amount of displaced charge (about three quarters of the total displaced charge $q_{\mathrm{D}}$ ). Therefore, the detailed analysis of the secondary signal part is performed by empirical fitting using two pairs of exponential functions of time (fast and slow time constants, $\tau_{\mathrm{f}}$ and $\tau_{\mathrm{s}}$ ) for parts A and B (green and blue curves at Fig. 6). The agreement between the measured data (circles) and the predicted values (fitted black curve) is very good. The value of root-mean-square deviation is about $0.023 \mu \mathrm{A}$ (which corresponds to about $6.2 \%$ of the maximum current value of the sum of individual curves, respectively). The total calculated displaced charge corresponds to $Q_{\mathrm{tot}}=Q_{\infty 1}+Q_{\infty 2}=1.37 \mathrm{nC}$, where $Q_{\infty 2}=Q_{\infty 2 \mathrm{a}}+Q_{\infty 2 \mathrm{~b}}$. The displaced charge, $Q_{\infty 2 \mathrm{a}}$, related to the signal part A is significant and corresponds to about one third of the displaced charge of primary signal part $\left(Q_{\infty 1}=0.32 \mathrm{nC}\right)$, while $Q_{\infty 2}$ is almost three times larger than 
the displaced charge of the primary signal part. Deviation of the calculated displaced charge, $Q_{\text {tot, }}$ from the experimental value, $q_{\mathrm{D}}$, is $0.08 \mathrm{nC}$, i.e. $6 \%$, which justifies separate analysis of the primary and the secondary parts of the signal.

\section{Discussion}

The elasticity of cell is a key parameter for the maintenance of the cell-envelope structure [30]. The nanomechanical properties of algal cells depend on their physiological state. AFM measurements revealed an age-related loss of elasticity and hydrophobicity of D. tertiolecta, which could be attributed to molecular modifications of the cell envelope. A change in the composition of the cell envelope has been reported for algae cultivated in different media [31]. Fatty acids isolated from Dunaliella show a dependence on salinity, where increasing salinity in the growth medium is correlated with the degree of fatty acid saturation, and thus with a reduction in the fluidity and permeability of the microalgal membranes.

The YM of a viable $D$. tertiolecta cell is low (19-31 kPa), since it lacks a rigid polysaccharide cell wall and is enclosed by a thin elastic plasma membrane $(0.9 \mathrm{~nm})$ covered by a mucous surface coat $[3,24]$. The effect of cytoskeletal structure on algal cell shape and mechanical properties is not considered to be very large [32]. In the case of Dunaliella, the cytoskeleton constitutes an integrated system, in which the basal bodies and their surrounding material are the central element. It is likely that the submembraneous network of microtubules maintains the elongated form of this cell. The YM of $D$. tertiolecta cells is comparable to that of mammalian cells [33-36]. In contrast, marine diatoms (e.g. Cylindroteca sp.) with a silica-based cell wall, have a YM about three orders of magnitude larger [9], and thus they are much more resistant to environmental stress.

Further, using chemically modified AFM tips, quantitative nanomechanical maps provide information on the distribution and magnitude of adhesion forces associated with the cell membrane. The hydrophobicity of microorganisms is directly correlated with the molecular composition of the cell surface, such as the surface coat proteins. The Dunaliella cell "coat" appears to be made up of glycoproteins of $\sim 150 \mathrm{kDa}$ existing in the outer layer surrounding cells, indicated by staining with cationic dyes [37]. According to the membrane proteome study of $D$. salina [38], these protein complexes may be surface coat proteins, lipid-metabolizing enzymes, ion transporters, GTP-binding proteins, heat shock proteins, or other membrane proteins of unknown function.

Physicochemical properties of cell surfaces and substrate interfaces influence the dynamics of adhesion and spreading. Table 1 compares the amperometric signals of cells in exponential phase and stationary [14] phase.

\section{Here Table 1.}

The amplitude and duration of the amperometric signal depends on cell size, while the shape of the signal depends on surface properties of the interfaces in contact. The signal duration for an algal cell in exponential phase is more than two times greater than that for a cell in stationary phase $(11.2 \mathrm{~ms}$ and $4.45 \mathrm{~ms}$, respectively). The total displaced charge for a cell in exponential phase is almost twice that of a cell in stationary phase (1.29 and $0.78 \mathrm{nC}$, respectively), which is in line with the larger cell volume determined by AFM measurements. Displaced charges of the primary signal parts are comparable for both signals of cells $(0.32$ and $0.39 \mathrm{nC})$. Displaced charge for the secondary part of the signal is about three times larger for cell in exponential phase (1.05 and $0.38 \mathrm{nC}$, respectively). Since the sum of calculated values of displaced charges for cells in exponential and stationary phase, $Q_{\infty 1}, Q_{\infty 2}$, agrees with the corresponding values, $q_{\mathrm{D}}$ (from Equation 1), of the complete analysed signals, the development of a methodology for separate signal analysis is justified. From the ratio between the cell volume determined from AFM measurements and the cell contact interface area $\left(A_{\mathrm{c}}\right)$ from amperometric signals analysis, it follows that the thickness of the final film at the interface is about $5 \mathrm{~nm}$. 
Time constants of the primary adhesion parts of the signals of the cells in exponential and stationary phases, $\tau_{0}$ and $\tau_{1}$, denoting attachment and deformation, are comparable, while the time constant $\tau_{2}$, corresponding to spreading, is two times slower for the cell in exponential phase $\left(\tau_{2}=0.51 \mathrm{~ms}\right.$ and $0.28 \mathrm{~ms}$, respectively). Time constants of the secondary signal parts $\tau_{\mathrm{s}}$ (considered as rate determining step) for the cells in exponential phase are significantly smaller than for cells in stationary phase $\left(\tau_{\mathrm{s}}\right.$ $=2.55$ and $1.04 \mathrm{~ms}$, respectively), which may be related to larger volume or stiffer cellular material, but also to a molecular reorganization in the film and an attenuated effect of potential over the modified interface.

Critical interfacial tensions for adhesion of $D$. tertiolecta depend on surface properties that vary with cell age. Critical interfacial tensions for adhesion of cell in exponential and stationary phases correspond to 398 and $390 \mathrm{~mJ} / \mathrm{m}^{2}$, and 396 and $383 \mathrm{~mJ} / \mathrm{m}^{2}$ at the positively and negatively charged interface, respectively. The decrease of critical interfacial tensions of adhesion for cells in stationary phase is in line with loss of cell hydrophobicity. These results are analogous with the decrease of critical interfacial tensions of adhesion of droplets of organic liquids with increasing chain length and polarity $[39,40]$.

\section{Conclusions}

Nanomechanical properties of algal cell govern interactions between cells and interfaces, thus they are important for understanding adhesion mechanisms and dynamics. AFM measurements reported here reveal that nanomechanical properties change during cell growth, and this is reflected in the interfacial adhesion dynamics. AFM results also show that D. tertiolecta cells are larger in exponential than in the stationary phase, which is in an agreement with the amperometrically determined larger amount of interfacial displaced charge. Finally, AFM results show that $D$. tertiolecta cells in the exponential phase are stiffer and more hydrophobic than those in the stationary phase, which suggests molecular modification of cell envelope during aging. Differences in the critical interfacial tensions of adhesion of cells in exponential and stationary phase are analogous with the adhesion behavior of hydrophobic droplets of organic liquids. Results obtained with the reaction kinetics model of the three-step process indicate that adhesion and spreading at the charged interface is slower when cells are in exponential phase, which may be attributed to larger volume and stiffer and more hydrophobic cellular material. Cell mechanical properties, as analysed here, may be considered as a marker for environmental stress, which may help to understand viability and adaptation strategies of algal populations in aquatic environments. A deep understanding of algal cell responses to environmental disturbances is essential for predicting how ecosystems may be affected by human activities. Additionally, knowledge of the nanomechanical properties of algal cells is of importance for the determination of the optimum electric field parameters necessary for efficient electro-extraction of valuble products such as biofuel and pharmaceutical compounds and further development of the biotechnological potential of microalgae [42-44].

\section{Acknowledgments}

This work was supported by the Croatian Ministry of Science, Education and Sports through the projects (i) 098-0982934-2744, (ii) Croatia-France bilateral programme Cogito (0411B014), and (iii) Grants provided by the French Centre National de la Recherche Scientifique (CNRS), the Agence Nationale de la Recherche (ANR), Project PIERGEN ANR-12-ASTR-0039, the Direction Générale de l'Armement (DGA) and the Midi-Pyrénées Région. 


\section{References}

[1] M.A. Borowitzka, Alternative culture and treatment systems, in: Perth, Western Austrralia, 1991: pp. 11-20.

[2] M.A. Borowitzka, L.J. (Lesley J. Borowitzka, Micro-algal biotechnology / edited by Michael A. Borowitzka, Lesley J. Borowitzka, Cambridge University Press, New York; Melbourne, 1988.

[3] A. Ben-Amotz, Bioactive Compounds: Glycerol Production, Carotenoid Production, Fatty Acids Production, in: A. Ben-Amotz, J. Polle, D. Subba Rao (Eds.), The Alga Dunaliella, Science Publishers, 2009: pp. 189-207. doi:10.1201/b10300-9.

[4] F. Pillet, L. Chopinet, C. Formosa, E. Dague, Atomic Force Microscopy and pharmacology: from microbiology to cancerology, Biochim. Biophys. Acta. 1840 (2014) 1028-1050. doi:10.1016/j.bbagen.2013.11.019.

[5] F. Pillet, C. Formosa-Dague, H. Baaziz, E. Dague, M.-P. Rols, Cell wall as a target for bacteria inactivation by pulsed electric fields, Sci Rep. 6 (2016) 19778. doi:10.1038/srep19778.

[6] M.J. Higgins, J.E. Sader, P. Mulvaney, R. Wetherbee, Probing the Surface of Living Diatoms with Atomic Force Microscopy: The Nanostructure and Nanomechanical Properties of the Mucilage Layer1, Journal of Phycology. 39 (2003) 722-734. doi:10.1046/j.15298817.2003.02163.x.

[7] M.J. Higgins, P. Molino, P. Mulvaney, R. Wetherbee, The Structure and Nanomechanical Properties of the Adhesive Mucilage That Mediates Diatom-Substratum Adhesion and Motility1, Journal of Phycology. 39 (2003) 1181-1193. doi:10.1111/j.0022-3646.2003.03027.x.

[8] M. Hildebrand, M.J. Doktycz, D.P. Allison, Application of AFM in understanding biomineral formation in diatoms, Pflügers Archiv - European Journal of Physiology. 456 (2008) 127-137. doi:10.1007/s00424-007-0388-y.

[9] G. Pletikapić, A. Berquand, T.M. Radić, V. Svetličić, Quantitative Nanomechanical Mapping of Marine Diatom in Seawater Using Peak Force Tapping Atomic Force Microscopy1, Journal of Phycology. 48 (2012) 174-185. doi:10.1111/j.1529-8817.2011.01093.x.

[10] V. Žutić, V. Svetličić, N. Ivošević, A. Hozić, O. Pečar, Northern Adriatic mesocosm experiment Rovinj 2003: dynamics of organic microparticles studied by the electrochemical technique, Periodicum Biologorum. 106 (2004) 67-74.

[11] V. Svetličić, N. Ivošević, S. Kovač, V. Žutić, Charge Displacement by Adhesion and Spreading of a Cell: Amperometric Signals of Living Cells, Langmuir. 16 (2000) 8217-8220. doi:10.1021/la0007832.

[12] N. Ivošević DeNardis, V. Žutić, V. Svetličić, R. Frkanec, Amperometric Adhesion Signals of Liposomes, Cells and Droplets, Chemical and Biochemical Engineering Quarterly. 23 (2009) 87-92.

[13] N. Ivošević DeNardis, J.P. Ilić, I. Ružić, G. Pletikapić, Cell adhesion and spreading at a charged interface: Insight into the mechanism using surface techniques and mathematical modelling, Electrochimica Acta. 176 (2015) 743-754. doi:10.1016/j.electacta.2015.07.068.

[14] Z.A. Levine, N.I. DeNardis, P.T. Vernier, Phospholipid and Hydrocarbon Interactions with a Charged Electrode Interface, Langmuir. 32 (2016) 2808-2819.

doi:10.1021/acs.langmuir.5b04090.

[15] I. Ružić, N. Ivoševic DeNardis, J. Pecar-Ilic, Kinetics of the Liposome Adhesion on a Mercury Electrode: Testing of a Mathematical Model, Nt. J. Electrochem. Sci. 4 (2009) $787-$ 793.

[16] I. Ružić, J. Pečar-Ilić, N. Ivošević DeNardis, Mathematical model for kinetics of organic particle adhesion at an electrified interface, Journal of Electroanalytical Chemistry. 642 (2010) 120-126. doi:10.1016/j.jelechem.2010.02.024.

[17] N. Ivošević DeNardis, V. Žutić, V. Svetličić, R. Frkanec, Adhesion Signals of Phospholipid Vesicles at an Electrified Interface, J Membrane Biol. 245 (2012) 573-582. doi:10.1007/s00232-012-9469-8. 
[18] R.R.L. Guillard, Culture of Phytoplankton for Feeding Marine Invertebrates, in: Culture of Marine Invertebrate Animals, Springer, Boston, MA, 1975: pp. 29-60. doi:10.1007/978-14615-8714-9 3.

[19] L. Chopinet, C. Formosa, M.P. Rols, R.E. Duval, E. Dague, Imaging living cells surface and quantifying its properties at high resolution using AFM in QI ${ }^{\mathrm{TM}}$ mode, Micron. 48 (2013) 2633. doi:10.1016/j.micron.2013.02.003.

[20] E. Dague, D. Alsteens, J.-P. Latgé, C. Verbelen, D. Raze, A.R. Baulard, Y.F. Dufrêne, Chemical force microscopy of single live cells, Nano Lett. 7 (2007) 3026-3030. doi:10.1021/n1071476k.

[21] D. Alsteens, E. Dague, P.G. Rouxhet, A.R. Baulard, Y.F. Dufrêne, Direct measurement of hydrophobic forces on cell surfaces using AFM, Langmuir. 23 (2007) 11977-11979. doi:10.1021/la702765c.

[22] E. Jauvert, E. Palleau, E. Dague, L. Ressier, Directed Assembly of Living Pseudomonas aeruginosa Bacteria on PEI Patterns Generated by Nanoxerography for Statistical AFM Bioexperiments, ACS Appl. Mater. Interfaces. 6 (2014) 21230-21236. doi:10.1021/am506241n.

[23] S. Kovač, R. Kraus, S. Geček, V. Žutić, Cell Suspension as a Model System for Electrochemical Analysis, Croatica Chemica Acta. 73 (2000) 279-291.

[24] V. Svetličić, N. Ivošević, S. Kovač, V. Žutić, Charge displacement by adhesion and spreading of a cell, Bioelectrochemistry. 53 (2001) 79-86. doi:10.1016/S0302-4598(00)00115$\mathrm{X}$.

[25] N. Ivošević DeNardis, V. Žutić, V. Svetličić, R. Frkanec, J. Tomašić, In Situ Amperometric Characterization of Liposome Suspensions with Concomitant Oxygen Reduction, 19 (2007) 2444-2450. doi:10.1002/elan.200703999.

[26] V. Žutić, S. Kovač, J. Tomaić, V. Svetličić, Heterocoalescence between dispersed organic microdroplets and a charged conductive interface, Journal of Electroanalytical Chemistry. 349 (1993) 173-186. doi:10.1016/0022-0728(93)80171-D.

[27] Israelachvili, J.N., Intermolecular and Surface Forces, Academic Press, New York, 1992.

[28] C. Formosa, M. Grare, E. Jauvert, A. Coutable, J.B. Regnouf-de-Vains, M. Mourer, R.E. Duval, E. Dague, Nanoscale analysis of the effects of antibiotics and CX1 on a Pseudomonas aeruginosa multidrug-resistant strain, Sci Rep. 2 (2012) 575. doi:10.1038/srep00575.

[29] V. Svetličić, A. Hozić, Probing cell surface charge by scanning electrode potential, Electrophoresis. 23 (2002) 2080-2086. doi:10.1002/1522-2683(200207)23:13<2080::AIDELPS2080>3.0.CO;2-W.

[30] R.J. Doyle, R.E. Marquis, Elastic, flexible peptidoglycan and bacterial cell wall properties, Trends Microbiol. 2 (1994) 57-60.

[31] X.-Q. Xu, J. Beardall, Effect of salinity on fatty acid composition of a green microalga from an antarctic hypersaline lake, Phytochemistry. 45 (1997) 655-658. doi:10.1016/S00319422(96)00868-0.

[32] A. Ben-Amotz, J.E.W. Polle, D.V. Subba Rao, eds., The alga Dunaliella: biodiversity, physiology, genomics and biotechnology, 1st ed, Science Publishers, Enfield (N.H), 2009.

[33] L. Chopinet, C. Roduit, M.-P. Rols, E. Dague, Destabilization induced by electropermeabilization analyzed by atomic force microscopy, Biochim. Biophys. Acta. 1828 (2013) 2223-2229. doi:10.1016/j.bbamem.2013.05.035.

[34] L. Chopinet, E. Dague, M.-P. Rols, AFM sensing cortical actin cytoskeleton destabilization during plasma membrane electropermeabilization, Cytoskeleton (Hoboken). 71 (2014) 587594. doi:10.1002/cm.21194.

[35] G. Smolyakov, B. Thiebot, C.C. Campillo, S. Labdi, C. Séverac, J. Pelta, E. Dague, Elasticity, adhesion and tether extrusion on breast cancer cells provide a signature of their invasive potential, ACS Appl Mater Interfaces. (2016). doi:10.1021/acsami.6b07698. 
[36] G. Smolyakov, M. Cauquil, C. Severac, V. Lachaize, C. Guilbeau-Frugier, J.-M. Sénard, C. Galés, E. Dague, Biophysical properties of cardiomyocyte surface explored by multiparametric AFM, J. Struct. Biol. 198 (2017) 28-37. doi:10.1016/j.jsb.2017.03.001.

[37] M.A. Borowitzka, Algae as food, in: Microbiology of Fermented Foods, Springer, Boston, MA, 1998: pp. 585-602. doi:10.1007/978-1-4613-0309-1_18.

[38] A. Katz, P. Waridel, A. Shevchenko, U. Pick, Salt-induced changes in the plasma membrane proteome of the halotolerant alga Dunaliella salina as revealed by blue native gel electrophoresis and nano-LC-MS/MS analysis, Mol. Cell Proteomics. 6 (2007) 1459-1472. doi:10.1074/mcp.M700002-MCP200.

[39] N. Ivošević, J. Tomaić, V. Žutić, Organic Droplets at an Electrified Interface: Critical Potentials of Wetting Measured by Polarography, Langmuir. 10 (1994) 2415-2418. doi:10.1021/la00019a064.

[40] N. Ivošević, V. Žutić, J. Tomaić, Wetting Equilibria of Hydrocarbon Droplets at an Electrified Interface, Langmuir. 15 (1999) 7063-7068. doi:10.1021/la990088y. 


\section{Authors' contributions}

FP performed cell culturing, AFM measurements, data analysis, wrriting the manuscript. ED participated and supervised nanomechanical measurements of algal cells, discussion, wrriting the manuscript. JPI contributed to development of methodology and application of reaction kinetics model for amperometric signal analysis, wrriting the manuscript. IR contributed to application of reaction kinetic model and corresponding empirical fitting of the amperometric signals, wrriting the manuscirpt. MPR supervised AFM measurements, participated in the writing of the manuscript. NID supervised the study, performed cell culturing, electrochemical measurements, data analysis, writting the manuscript. All authors read and approved the final manuscript.

\section{VITAE}

Flavien Pillet born in 1982, received a $\mathrm{PhD}$ in 2010 from the "Institut National des Sciences Appliquées" of Toulouse, France. His main research interests are the study of biomolecular interaction by Surface Plasmon Resonance, the microorganism survey by Atomic Force Microscopy and the influence of pulse electric fields on microorganisms and model membrane vesicles. Since April 2013, he is in posdoctoral position fellow at the "Institut de Pharmacologie et Biologie Structurale" in the Cellular Biophysics group.

Etienne Dague received his $\mathrm{PhD}$ in physico-chemistry from Université Henri Poincaré, Nancy, France. He then moved to Belgium for a post-doctoral stay in Université Catholique de Louvain. He has been hired in France as a permanent researcher at LAAS-CNRS, Toulouse. He developed activities dealing with the interactions occurring at the surface of living cells: mechanical interactions, recognitions, drugs interactions etc. He has been responsible for an interdisciplinary team at ITAVCNRS focusing on nano cardiology and biophysics of cancerous cells. He now conducts an ANR project on GPCRs and has different international collaborations concerning the applications of AFM.

Jadranka Pečar Ilić finished her $\mathrm{PhD}$ studies in electrical engineering and computing at the University of Zagreb, Croatia in 2001. She is a senior research associate at the Ruđer Bošković Institute, Zagreb and in 2012 she was promoted to associate professor at the Faculty of Electrical Engineering and Computing, University of Zagreb. She works in environmental informatics applied to air and water quality, risk management and inland navigation. Her research interests include conceptual modelling of processes, data integration and spatial-temporal visualization, environmental information systems, web applications and services.

Ivica Ružić is a senior researcher (full professor, retired) at the Ruđer Bošković Institute, Zagreb. He finished PhD studies in chemistry at the Faculty of Science, University of Zagreb in 1971. Visiting scientist: the Northwestern University, Evanston, Ill, USA, 1972-1975; University of Utrecht, NL, 1977; the Netherlands Institute for Marine Research, Texel, NL, 1983; the University of Aarhus, DK, 1993. His research interests are mathematical modelling of electrode processes and chemical processes at geological and biological interfaces, environmental informatics, intelligent waterborne traffic information systems and wireless communication between sensors and automatic measuring devices.

Marie-Pierre Rols obtained her PhD in Biophysics at the University of Toulouse, France. She is a senior scientist at the Institute of Pharmacology and Structural Biology of the CNRS, Toulouse. She is head of the Cellular Biophysics group and of the Structural Biology and Biophysics department. Her research interests lie in the fields of electroporation in cells and tissues. She is involved in different aspects including the mechanisms and applications. She develops for many years a 
multidisciplinary approach combining Cell Biology and Biophysics using various imaging tools to visualize and define these phenomena at the molecular level on different.

Nadica Ivošević DeNardis is senior research associate at the Division of the Marine and Environmental Research, Ruđer Bošković Institute, Zagreb, Croatia. She finished PhD studies in chemistry at the Faculty of Science, University of Zagreb in 1997., followed by postdoctoral work as a Fulbright fellow at the Department of Marine Science, University of Connecticut, CT, USA. Her research interests are: surface properties of soft particles (cells, lipid vesicles, organic droplets); adhesion and spreading of soft particles at the interface using complementary surface methods (electrochemical and atomic force microscopy) and modelling. 